\title{
El caciquismo como tema de debate en la opinión pública: la actitud de la prensa sevillana en 1923 y 1931
}

\section{CONCHA LANGA NUÑO}

No cabe duda que la fuente hemerográfica' ofrece un particular interés a la hora de aproximarse al pulso de una sociedad en la Edad Contemporánea. Por ello, una vía para acercarse a cualquier fenómeno de esta etapa histórica es la de acotar la opinión "pública" o "publicada" a través de la información ofrecida por los periódicos, teniendo en cuenta sus diferentes ideologías. Hacerlo con la primera mitad del siglo XX equivale a establecer un ejemplo y a concurrir metodológicamente sobre la base de sus especiales acontecimientos. Y lo es en razón a que, entre otros, el tema del caciquismo, -planteado entonces con toda su crudeza-, cubrió un amplio espacio en el debate de juicios que se entabló en esas fechas.

El objetivo de la presente comunicación consiste en trazar una somera reflexión acerca de cómo apareció en la prensa sevillana la cuestión tan denostada del caciquismo en el momento de la proclamación de la República de abril de 1931, partiendo del supuesto que los mensajes de la opción antimonárquica en esos momentos hicieron suya la crítica al caciquismo y se presentaron como la fórmula capaz de resolver el problema. Ahora bien, como se verá ese planteamiento no viene a coincidir con lo que realmente expresaron los periódicos hispalenses en aquellas jornadas. Por sorprendente que parezca; la conducta de $E l$ Correo de Andalucia, El Liberal, El Noticiero Sevillano, La Unión y $A B C$ al respecto no muestran coincidencias absolutas con la idea anterior.

En virtud de tales actitudes en tan diversas líneas de "opinión", el segundo componente de esta Comunicación, como trazo comparativo de mayor riesgo, concreta un análisis de los editoriales publicados por esa misma prensa con ocasión de la dictadura de Primo de Rivera en 1923, y en la que, por el contrario a lo ocurrido en 1931, las alusiones y ataques al caciquismo, sí fueron muy importantes.

Por consiguiente, una Comunicación centrada en un examen acerca del diferente tratamiento del mismo fenómeno en dos momentos tan 
crucizles y cercanos del siglo XX español. La cuestión podría resumirse en las consideraciones a extraer de la siguiente pregunta: ¿Había sido superado el problema del caciquismo como asunto de debate público en 1931 o simplemente habíaperdido importancia como reclamo político ante la tensa disyuntiva de Monarquía y República?

En orden inverso a los esquemas mentales seguidos en el planteamiento de esta Comunicación, y ajustándome así a un esquema cronológico, comenzaré con la observación del periodo 1923, y más concretamente los relacionados con el pronunciamiento militar del 13 de septiembre que llevaron al poder la Dictadura de Primo de Rivera.

Lejos de mi propósito el intentar explicar, en esta breve aproximación, los motivos que provocaron este pronunciamiento. Diversos investigadores han dedicado numerosas páginas al tema. Sin embargo, es evidente que no se puede plantear qué tipo de reacción manifestó la "opinión pública" hispalense sin trazar una mínima introducción acerca de lo que motivó y supuso el acontecimiento a escala nacional, y desde ahí, cubrir el espacio sevillano.

De hecho, parece oportuno distinguir que, en el momento inmediatamente anterior al mencionado pronunciamiento, el país se veía afectado por imnumerables problemas fruto de muchos años de inestabilidad gubernativa y de desajustes entre la llamada "España real" y la "España oficial". Las mayores fisuras se encontraban, para Pierre Malerbe ${ }^{1}$, entre la nueva masa obrera que ocupaba las ciudades, (consecuencia del incremento de la industrialización y de la emigración rural, y agrupada en las diferentes organizaciones sindicales), y el campesinado subyugado por el caciquismo. En concreto, en un clima de crispación se desarrollaron las elecciones de diciembre de 1922 con la Concentración Liberal de Santiago Alba en posición destacada y, al fin, García Prieto como nuevo Presidente del Gobierno. Un Gobierno, elegido siguiendo los mecanismos clásicos del sistema oligárquico,y que se presentó con un programa político innovador, al menos en teoría. Recuérdese que tomó medidas de no muy buena acogida en los sectores influyentes ya por encaminarse a una mayor laicización del Estado, ya por su proyección civilista y de control militar. En este sentido, la sustitución de militares por civiles en puestos tradicionalmente copados por aquellos y, además, de gran importancia como eran el de Gobernador Civil de Barcelona y el de Alto Comisario de Marruecos no pasó desapercibida y suscitó fuertes controversias. Medidas que crearon malestar en las esferas eclesiásticas y militares, con el añadido de las

(1) VVAA; La Crisis del Estado: Dictadura, República, Guerra. (1923-1939) Tomo IX de la historia de España dirigida por D. Manuel Tuñón de Lara. Editorial Labor, Barcelona 1981. Pág. 32. 
incertidumbre en éstas en cuanto a la próxima publicación de las responsabilidades por el desastre de Anual. En suma, un desasosiego coincidente con el de una "opinión pública" en actitud de desprecio hacia el sistema político vigente por sus métodos oligárquicos y caciquiles, utilizados de forma absolutamente descarada en esas elecciones, (el encasillado se hizo públicamente y en nada se disimuló el sistema de clientelismos políticos). Portodas estas razones, Tusell afirma lo siguiente:

"...En todo caso, lo que resulta evidente es la dificil situación en que se ha colocado a sí misma la "vieja política" a la altura de 1923, (...) Se dan, por lo tanto, las condiciones óptimas para que tenga lugar un acontecimiento como el que efectivamente va a producirse: el advenimiento de una dictadura regeneracionista y anticaciquil."

Visto lo anterior, cabe preguntarse qué ocurría en la capital hispalense. Respecto de la Sevilla de la Restauración se sabe, -los estudios de Alvarez Rey y de María Sierra lo clarifican-, que funcionó totalmente integrada en el sistema político turnista. En sí, desde comienzos de siglo, los dos partidos usufructuadores del poder se encontraron liderados por las importantes figuras de Eduardo y Tomás Ybarra en el conservador, y Pedro Rodríguez de la Borbolla en el Liberal. Este último es considerado como modelo de cacique por su dominio de la política ciudadana. Ahora bien, llegados a la fecha de 1920 la desaparición de tan fuertes personalidades se había traducido en una crisis en ambos partidos, mucho más profunda en el Liberal fraccionado entre los seguidores de Santiago Alba y los romanonistas, crisis que revirtió positivamente en el dominio de la parcela de poder ocupada por los conservadores regidos por Carlos Cañal. Y no solo eso. A los problemas internos de tales partidos se unió el desarrollo de una oposición, de diferente matiz. A la izquierda, los republicanos de Martínez Barrio que parecían estar en un momento muy pujante; un precario Andalucismo político de confusas inquietudes, y unos grupos socialistas, con el P.C.E. fundado en 1921, de muy exigua fuerza. A la derecha, un abanico más amplio incluyendo a los carlistas, cada vez menos importantes; los mauristas; la Liga Católica, (derecha católica sevillana, dirigida hasta su muerte en 1920 por Manuel Rojas Marcos); y el Partido Social Popular, de Illanes y Giménez Fernández. Coaligados estos diversos grupos en 1922, serían "quien en realidad aglutinaba a la derecha política sevillana en las primeras décadas del siglo"

(2) Javier TUSELL; Oligarquia y Caciquismo en Andalucia, (1890-1923). Editorial Planeta. Barcelona 1976. Pág. 588.

(3) Leando ALVAREZ REY; Sevilla durante la dictadura de Primo de Rivera. La Unión Patriótica sevillana. 1923-1930. Excma. Diputación de Sevilla. Sevilla 1987. Pág. 44. También, BRAOJOS, PARIAS, ALVAREZ REY; Sevilla en el siglo XX, (1868-1950). Universidad de Sevilla, Sevilla 1990. 
renunciar a su carácter de asociación patronal, optó por un compromiso político en conducta de acérrima oposición a la oligarquía y al caciquismo. Con todo, semejante coalición de "derechas" careció desde el principio de solidez, de modo que, en su fragilidad, enrareció todavía más el ambiente de la política hispalense en aquellos instantes. En resumen, unas "izquierdas" y unas "derechas" atentas a presionar a fin de conseguir un giro en la tendencia de losbloques políticos sevillanos dominantes hasta entonces y opuestas, sin reservas, a lo que configuraba el caciquismo.

Basten estas escuetas líneas para tener una mínima noción acerca de la imagen de la política ciudadana del verano de 1923. Aquella que se desenvolvía entre el miedo a un nuevo ataque de Abd-el-Krim o a la vuelta de una oleada revolucionaria campesina u obrera como la vivida entre 1917-1920, y la decepción por las rivalidades personales de los políticos, sobre todo de los liberales, a más del desencanto de la oposición ante su impotencia frente al anquilosamiento del sistema. Una situación que no la llevaba a ninguna parte.

Así se llegó a ese 13 de Septiembre de 1923 en el que las noticias cundieron de forma bastante confusa. Se supo que algo estaba pasando en el Gobierno pero no exactamente qué. La incógnita provocó una excepcional expectación y bastantes especulaciones. Los diversos organismos políticos sevillanos, tras numerosas reuniones, decidieron expresar su lealtad al Monarca, al igual que Capitanía General por voz del Infante Don Carlos. De modo que, cuando el día 14 se conoció la postura del rey, Capitanía optó por proclamar el "estado de guerra" lo que hizo a las diez de la noche. Al conocerse la noticia, numeroso público se aglomeró ante las puertas del cuartel de la plaza del Duque prorrumpiendo en ¡Vivas! al Rey, al ejército y a Primo de Rivera, y ¡mueras! a los políticos; escenas repetidas en los cuatro puntos de Sevilla donde se leyó el bando con la disposición, formándose también una manifestación a las puertas de Capitanía.

Como puede observarse, la respuesta a nivel popular fue inmediata y positiva mas, ¿cómo reaccionó la prensa?, ¿cuál fue la opinión en ella vertida?. En este sentido, me voy a centrar no solo en lo publicado en sus páginas inmediatamente después del golpe sino también en lo inmediatamente anterior para establecer si hubo o no cambios en su opinión. En ese propósito, me ha interesado distinguir si el problema del caciquismo aparece en estos momentos y, si lo hace, cuál fue su tratamiento y su importancia como tema de debate o crítica. Para ello, a continuación analizaré las fuentes consultadas diferenciado su carácter y orientación editorial, si bien es lástima no poder contar con El Noticiero Sevillano al no hallarse entre los fondos conservados. Por orden de antigüedad la serie sería la siguiente: 
El Correo de Andalucía "diario católico de noticias", fundado en 1899 a instancias del cardenal Spínola, arzobispo hispalense. Desde su origen y como es fácil de comprender fue el órgano de la derecha católica sevillana y, de esta forma, contó entre sus patrocinadores con personajes políticos tan importantes como Manuel Rojas Marcos (jefe de la Liga Católica hasta su muerte), y José María López-Cepero presidente del Partido Social Popular y, más tarde, jefe local de la Unión Patriótica sevillana. Dada la ideología de este diario no debe extrañar que fuese élprimero en mostrar sin reservar su satisfacción por el golpe de estado de Primo de Rivera el día 14 cuando aún no se conocía exactamente la situación del país. De ese modo, en un editorial titulado "Solución única", el diario no dudó en decir; "no es imprudente afirmar que España entera acoge con simpatía el brioso intento de barrer la basura política que se ha enseñoreado del país". Llama la atención que, sí inmediatamente antes del pronunciamiento no se encuentran artículos de opinión destacables en él, a partir de este momento incluyera muchos destinados a proclamar lo muy positivo de la nueva situación. En todos se muestra el regocijo con la cual ha sido acogido el cambio, en todos ellos aparece como algo necesario e inevitable debido a los malos usos políticos anteriores, $y$, finalmente, en todos se afirma la esperanza en un futuro mejor para la Patria.

Con respecto al primer punto, sobresale que el conjunto de los artículos, la mayoría firmados, no ofrecen duda acerca de la total adhesión de El Correo al golpe: "que la nueva situación gobernante ha encontrado cordial y simpática acogida en la opinión pública, es notorio -llegó a decir-. Ese sentimiento lo hemos recogido de hombres de todas las clases sociales y de muy diversas tendencias políticas"s. El segundo punto, lo necesario del golpe lo define en oposición a la política existente con anterioridad. De este modo, España necesitaría ser salvada -según éldel desastre anterior: "Por ello, falta de rectores, sin timón y sin rumbo, España navegaba a merced de la fuerza de las alborotadas aguas. $Y$ ahora ¡casi sin un golpe de fuerza! al eco de una voz fuerte, en la que se han reunido los ahogados clamores del país, ha echado a tierra aquellos embelecos que simulaban gobierno, autoridades y partidos políticos"6. Esas fueron sus palabras. De ahí que sean los políticos y sus manejos el punto más criticado en estos artículos de El Correo que repiten sin cesar y hasta en tono apocalíptico lo positivo de lo que califican como su 'caída': "El alcázar liberal, que hace tantos y tantos años albergaba a las

(4) El Correo de Andalucia 14-IX-1923

(5) Ibidem, 16-IX-1923

(6) Ibidem 
diferentes dinastías políticas, ha caído con estrépito, como en otros tiempos las murallas del Jericó, al son de las cornetas y tambores pregoneros de la ley marcial, y ante el solo temor de que las espadas vengadoras de los militares atravesaran a los que se creían sus dueños y eternos moradores". Con idéntico espíritu y respecto a la inevitabilidad del pronunciamiento, -"ha venido porque tenía quevenir"-, surge el problema de su legalidad. En este sentido destacan dos artículos del miembro del Partido Social Popular, Víctor Pradera, cuyos términos no ofrecen duda: "No: en el conflicto entre la legalidad formal y la vida nacional ésta ha de triunfar, como entre el conflicto entre la vida del agredido y la del agresor es de derecho natural que triunfe la primera, aun a costa de un material homicidio"s, cree que si la vida de la Patria peligraba, la defensa de la misma estaba por encima de todo. Finalmente, en relación con las esperanzas en un futuro mejor bajo la dictadura de Primo de Rivera, se confía por un lado en el cambio de sistema político: "Reorganizados el Gobierno, las Cortes y la nación, hay que reorganizar, por último, la vida ciudadana, mediante la reorganización de la justicia." decía Víctor Pradera, atacando, incluso al parlamentarismo en sí; "El parlamentarismo, el funesto sistema colector de mil errores y ruina de la Patria..." . Fiel a ese enfoque $E l$ Correo jugaba que, pese a todo, no tendría validez si no se actuaba con nuevos. "hombres de buen sentido, de recia y buena voluntad..." ${ }^{\text {. }}$."Que los que manejan las riendas permanezcan en guardia el tiempo que sea preciso, con los aceros desnudos, junto al alcázar derruido que guarda entre sus escombros a los ídolos rotos, para que ninguno se mueva, nadie se rehaga; porque un nuevo sol de justicia y de verdad ha aparecido en el horizonte azul de nuestra Patria, que iluminará a todos por igual, y cada cual "calentará" según su merecido"11.

Vistos estos puntos, conviene preguntarse ahora: ¿trató El Correo el tema del caciquismo? En caso afirmativo, ¿̨cómo lo hizo? ciertamente hay que decir que sí y de forma reiterada. El tema lo incluye vinculado a los males pasados del país y que necesitaban ser combatidos urgentemente para asegurar el triunfo del nuevo sistema. Sirva de ejemplo sus afirmaciones del 16 de septiembre: "Aún deshechos los partidos políticos, sus tentáculos tiene por si mismos fuerza suficiente para mantener, mediante la opresión, el tinglado de la farsa. Mientras no sea exterminada políticamente la nube de caciques y caciquillos que ensombrece el patrio solar,

(7) Ibidem, 28-IX-1923

(8) Ibidem, 25-IX-1923

(9) Ibidem, 20-IX-1923

(10) Ibidem, 27-1X-1923, artículo firmado por Miguel Peñaflor.

(11) Ibidem, 28-IX-1923, Artículo firmado por Blas González Lizarralde. 
nadie espere que el país dé hombres nuevos". Más aún, subrayaba: "El Caciquismo! ese es el enemigo de España con el que se debe acabar y se puede acabar en quince días.". Curiosamente, en ese mismo artículo hay una disculpa para estos corruptores de la Patria; "Porque es cierto que hay en la política española hombres perversos, dañosísimos; pero, en su mayoría, ellos son las primeras víctimas del sistema. Es el régimen quien los corrompe, quien los fuerza a ser tiranos, nepotistas y conculcadores de la ley. Y mientras el sistema no se transforme de arriba a abajo, los buenos se tornarán malvados o fracasarán"12. De cualquier forma, la crítica y ataque pidiendo la rápida desaparición de las fórmulas caciquiles, en todos los sectores de la vida pública, es la tónica general del diario en aquellas jornadas, "sabiendo que hay caciques y que es menester exterminarlos y no halagarlos"13. En la denuncia del asunto destaca un texto. Su título, "Hay que terminar con el caciquismo!". Firmado por Antonio Gómę-Coronado, comenzaba en los siguientes términos; "Todos los buenos españoles debemos considerar a los ćaciques como unos enemigos del bien común, y como tales hay que tratarles hasta hacerlos que resistan formalmente de abusar de la paciencia de los pueblos y renuncien a su antipático oficio de tiranos o tiranuelos de los mismos, pues, como sabemos, hay grandes caciques que extienden sus tentáculos sobre extensas regiones, y otros, que, por no haber podido llegar a tanto, tienen que conformarse con explotar y atosigar al pueblo donde residen." A criterio del autor habría que acabar con ellos "de una manera decidida, enérgica y sin contemplaciones, (...) desmontar todos los instrumentos de que hasta ahora se han servido para tiranizar y enriquecerse." Es decir, proponía una exigencia de responsabilidades desde la inspección de la administración por ellos ejercida y de sus fortunas personales, hasta la designación de nuevos alcaldes representativos y de jueces municipales, pasando por la reforma radical del procedimiento electoral. Las medidas son radicales. Por último hacía un llamamiento al "Cuerpo electoral de esta provincia para que ya que en las últimas elecciones de las disueltas cortes dió la sensación de soportar sumisamente el más arraigado y despótico caciquismo, (...) demuestre ahora ante el país que no somos una provincia sin conciencia colectiva, aprestándonos todos a poner de nuestra parte todo cuanto den de sí nuestras energías para combatir, hasta exterminarlo, el absorbente, repulsivo y tiránico caciquismo que hemos padecido"14. He aquí cual fue la postura de $E l$ Correo de Andalucía.

(12) Ibidem, 16-IX-1923

(13) Ibidem,27-IX-1923

(14) Ibidem, 29-IX-1923 
El Liberal, "diario de información general" fue fundado en $1901 \mathrm{y}$, desde 1922, perteneció a una empresa madrileña propiedad de los hermanos Busquets. Su dirección entre 1909 a 1936 estuvo en manos del prestigioso periodista José Laguillo Bonilla. En este diario se encuentra una gran preocupación por los problemas del Municipio, como muestran los editoriales más cercanos cronológicamente al golpe. En entre ellos destaca el dedicado a la falta de designación de gobernadores civiles en el que el periódico no se contenta con llamar la atención sobre los efectos negativos, sino que se atreve a criticar abiertamente las causas del mismo, -"un politiqueo de entre bastidores, cuyo tira y afloja no acaba nunca"-, ofreciendo soluciones: "Vista la práctica, sería lo mejor, ó suprimir el cargo, o preparar una promoción de gobernadores técnicos que, administrativamente y a su turno, desfilaran por el cargo, aun cuando se chincharan las elecciones y los candidatos de casa y boca"15. Así, podemos observar que las críticas al sistema y a los manejos oligárquicos aparecen de forma clara y definida el mismo día del golpe de Primo de Rivera, a pesar de no conocerse claramente su existencia.

Ese cansancio y desconfianza en el sistema de la Restauración es lo que puede explicar la reacción ante un golpe de estado de origen militar por parte de un diario de ideología liberal, el cual recibió positivamente el pronunciamiento afirmándose Laguillo, el día 15 , en estos términos; "A la depuración y predominio del Poder Civil debemos aspirar. Y la ruta más corta será la mejor y la más justa"16. A partir de este momento aparece una serie de artículos y editoriales en la que se habla de las esperanzas en el nuevo sistema o sobre las decepciones del anterior. Respecto de las primeras, se confía en la justicia del nuevo régimen para realizar la "redención" de la Patria, permitiéndose el diario sugerir cuales han de ser los objetivos inmediatos: subsistencias, higiene y viviendas. A ello dedica algunos editoriales ${ }^{17}$ invocando siempre a la capacidad ejecutora del nuevo poder y a su afán de justicia: "Esta justiciera dictadura, de seguro, no encontrará siquiera ni un detractor, como no sean aquellos que explotaban y viven del injusto sistema actual"18. Al mismo tiempo, y tras conocerse la destitución del antiguo ayuntamiento, le asiste la preocupación por saber a dónde va el nuevo municipio, siempre con el deseo y la confianza de mejorar lo anterior. Dicha labor es tomada por este periódico de forma absolutamente consciente, cosa que se puede observar en el artículo titulado "Sevilla y la nueva situación. A laprensa

(15) El Liberal 13-1X-1923

(16) Ibidem,15-IX-1923.

(17) Ibidem,18-19-23- IX-1923.

(18) Ibidem, 19-IX-1923. 
corresponde el mayor esfuerzo", publicado el día 22 y que comenzaba del siguiente modo: "Desaparecidos los intermediarios con el Poder Central que representaban parlamentariamente a esta provincia, corresponde a la Prensa una mayor actividad política al eco de las aspiraciones ciudadanas y elevarlas a las esferas oficiales" ${ }^{\prime 19}$.

Entre esos artículos de El Liberal destacan los firmados por el director del mismo, José Laguillo por ser un compendio del pensamiento de, seguramente, una facción de la sociedad sevillana de mayor influencia. En ellos expone con claridad sus anhelos de futuro y sus decepciones del pasado. Resumen de sus ideas sería el siguiente párrafo: "Donde no hay ciudadanía, es decir, pueblo, foco de las sanciones supremas, tiene que haber la sanción transitoria y momentánea de otro poder que en su nombre restablezca la justicia y derroque los excesos oligárquicos" ${ }^{20}$, pero... "si no hay ciudadanía es porque la política hizo de ella inocuo comercio"21. El Liberal forma asi un círculo vicioso, en el que el culpable de los males del país sería en primera y última instancia el sistema político, y dentro de éste los políticos profesionales: "Los directores del sistema se tranquilizaban sabiendo que podian contar con la impunidad. 'Detrás de mi el diluvio', era la fórmula de cada uno de los grupos políticos en la situación del Poder y de cada uno de los individuos que lo integraban"22. Laguillo no duda ni un momento de la soberanía del pueblo; pero..."la inhibición de todos es la que ha hecho funcionar al único instrumento hábil y apto"23. Es por ello que un hombre de tan profundas ideas liberales apoya un golpe militar de este tipo: "Ahora lo que importa es la labor, el procedimiento, los frutos. Nuevos hombres han de traer otras normas. Y conductas más puras han de madurar en un nivel más alto de bienestar público y paz general"24.

Dentro de este profundo desencanto hay un tema que aparece ref -tidamente en sus artículos: la crítica aloligarquismo y al caciquismo anterior. 'Excesos', 'fariseísmo', 'corrupción desmoralizadora', 'castas', 'ambición e ineptitud', etc. son algunos de los términos con los que se refiere al sistema de la Restauración. Aparte de la crítica sistemática, trata de diferentes maneras el problema. Por un lado, la existencia de la oligarquía y el caciquismo serían una de las 'excusas' o motivos para aceptar el nuevo régimen, como se ha visto, y estaría sustentada en la posibilidad

(19) Ibidem, 22-IX-1923.

(20) Ibidem, 15-IX-1923. El nombre del artículo es: "El corolario de una sistemática inhibición. Debemos aspirar al predominio del poder civil."

(21) Ibidem, 20-IX-1923.

(22) Ibidem.

(23) Ibidem, 15-IX-1923.

(24) lbidem 16-IX-1923. 
de realizar; "la política moderna, en la que, los aptos y los especializados, los mejores, no las castas y las familias de profesionales oligarcas que, dueños de la impunidad, compatibilizaban la ambición y la ineptitud con la decadencia y los desastres de la Patria"2s. De este modo, sí de un lado espera que el cambio de los hombres sea suficiente para cambiar las actitudes políticas, Laguillo sigue manteniendo sus reservas en el mismo artículo: "Los tentáculos del oligarquismo en que la nación vegetaba eran muy fuertes y múltiples para que al cortarlos con la espada tajante de las resoluciones heroicas no abriguemos el temor de que puedan ser lesionados inconscientemente algunos de los órganos oprimidos". Este realismo reaparece después de conocer el cese de los ayuntamientos: "Nadie ignora como se ahonda en las capitales y en los pueblos la raíz del caciquismo generado por las pasividades de la ciudadanía; (...) En los ayuntamientos y, sobre todo, en las Municipalidades pequeñas, hoy sujetas al yugo del más bajo caciquismo, es donde encontramos difícil la acción renovadora. De esa forma, el director de El Liberal, tras la confusión de los primeros dias reconoce la hondura de la implantación del sistema y, por consiguiente, la gran fuerza que se va a necesitar para superarlo. Para ello, mantiene gran confianza en el siempre llamado paréntesis: "Porque la solución no está en las personas; está en el régimen que se establezca y en la eficiencia de como se aplique, para que no sean posibles corruptelas..." ${ }^{26}$. Hasta aquí la opinión de el diario El Liberal, sobre la implantación del nuevo régimen y del caciquismo existente.

Finalizando con los periódicos consultados para este periodo corresponde el análisis a La Uniôn. Este "diario independiente", fundado en 1918, bastante vinculado a las máximas personalidades de la Unión Comercial, se convirtió en su órgano de opinión. En él, y bajo el epígrafe "Del Momento", se encuentran un grupo de editoriales, la mayoría no firmados, de gran interés por los juicios vertidas. Ya en los instantes inmediatamente anteriores al pronunciamiento aparecen en ellos los temas principales barajados tras el mismo, afirmándose laexistencia de "indicios vehementes de que se aproxima algo catastrófico"27 al hacer referencia al conflicto marroquí, a la depreciación de la moneda, y al separatismo catalán. En todos se observa una profunda preocupación por el estado en que se encuentra España en ese periodo, haciendo llamamientos encaminados a su salvación. En ese sentido, es atacado como uno de los principales causantes de las enfermedades patrias el caciquismo, "odioso sistema de castas privilegiadas", "cáncer"... Como paliativo

(25) Ibidem, 16-IX-1923.

(26) Ibidem, 28-IX-1923.

(27) La Uniôn, 7-IX-1923 
de tales calificativos, se propone una acción importante de corporaciones como las Cámaras de Comercio, las asambleas de productores etc., a más del llamamiento a la lucha de las clases neutras. No hay que olvidar que en estos momentos la Unión Comercial había entrado de lleno en el mundo político de la mano de los conservadores.

Llega en este ambiente, corporativista y regeneracionista, el golpe de Estado de Primo de Rivera. La reacción del periódico ante el mismo aparece en un artículo el día 14 bajo el título "La Dictadura, No!". Como nota cabe subrayar que es este el único diario que parece rechazar el pronunciamiento primorriverista. Sin embargo, leyendo atentamente su contenido se llega a la conclusión opuesta. Cierto es que no está de acuerdo con una dictadura militar, pero cierto también que no se conforma con el sistema existente. Por ello: "excepto algunos alardes fanfarrones, que pudieron y debieron ser eliminados del escrito y separando también la parte 'dispositiva', nosotros suscribimos el manifiesto, porque es la repetición de muchas ideas y patrióticos anhelos que hemos expresado diferentes veces." Por esto, termina pidiendo el desahucio de los políticos de oficio y el que sean los militares quienes copen el poder hasta la llegada de civiles capacitados para ello. Concluye con un "Guerra a los políticos y ¡Viva España!"28.

En artículos posteriores la actitud positiva hacia el nuevo régimen se acentúa. En sus textos se observa la esperanza de que sea el instrumento para todos aquellos anhelos que aparecían en los artículos precedentes. Así, pide con fuerza la existencia de un sistema corporativo en el que, desaparecidos los políticos profesionales corruptos, las Cortes puedan desarrollar una labor positiva para el país. Por otro lado, ya no invoca los grandes problemas nacionales. Ahora se limita a proponer posibles medidas a tomar para mejorar problemas presentes e inmediatos, (desde el cierre de las tabernas como centro de nefastas tertulias políticas y de vicios deleznables, al uso del servicio militar para formar y alfabetizar, el reajuste de las academias, la mejora de la política de subsistencias, o el control de la leche para evitar la gran mortalidad infantil... etc.).

Entre esos artículos de La Unión, el tema tan repetido y denostado del caciquismo aparece tangencialmente en relación con la necesidad de cambio del sistema y de la nueva labor moralizadora. Respecto al último aspecto, el ataque lo hace directo a los anteriores grupos políticos y sus formas: Pide ayuda a los ciudadanos para que apoyen a la Dictadura en dicha labor ante el temor de una continuación de su poder: "Los grupos políticos, puestos en acecho de oportunidades favorables a su venganza

(28) Ibidem, 14-IX-1923 
y medro, fomentarán toda inclinación a la protesta y harán añorar a los detenidos en su carrera de desenfado aquella edad dorada, en donde todos vivían en paz, aunque ésta no fuera precisamente la paz de espíritu que dimana de la tranquilidad de conciencia, sino en la resultante de hacer cada uno lo que más beneficio le reporte..., con la condición de tener algún personaje o personajillo nada más que le ampare bajo su manto protector" 29 .

Hasta aquí, las diversas "opiniones" vertidas en la prensa hispalense en los momentos que rodean el pronunciamiento militar de Primo de Rivera. En los diversos diarios se observa, sin duda, una gran homogeneidad de opinión a pesar de su diversa ideología. Todos critican el sistema de la Restauración, todos apuestan por el cambio y, con énfasis, todos estiman que el caciquismo, como manifestación oligárquica, es uno de los mayores males que viene padeciendo el país, por lo que se hace vital su urgente extirpación. Convierten de este modo el caciquismo en una de las disculpa para la aceptación de un "cirujano de hierro".

Vista la primera época elegida para esta síntesis por su importancia histórica acoto ahora un segundo momento de, inclusive, mayor impacto para la vida de la nación: el advenimiento de la República. Como es bien sabido, éste se produjo de forma algo "anormal", tras unas elecciones municipales cuyo proceso ha sido también de sobra estudiado. Baste decir que la caída de la Dictadura llevaba a un callejón sin salida por, entre otras causas, la grave crisis económica que, con sus secuelas de tensiones sociales, se proyectó sobre España. Se produjo así, un cambio en la "opinión pública", manifestado en las revueltas estudiantiles y en la ausencia de confianza de los militares ante la figura del dictador. Por estos motivo, Primo de Rivera dimitió el 28 de enero de 1930, iniciándose un periodo de transitoriedad con el gobierno del General Berenguer. Sin embargo como dice Alvarez Rey:

"El problema político en que se debatía el país permanecía inalterable, con el agravante de que la España de 1930 no era ya la de seis años atrás: la dictadura había vacunado a muchos españolescontra el miedo a la República, idea que se configura ya como una alternativa viable al caduco sistema de la Restauración que el general Berenguer piensa volver a implantar. Desaparecido Primo de Rivera, quien estaba en peligro era el propio rey. (...) lo que va a dilucidarse a partir de entonces es la

(29) Ibidem 26-IX-1923 
continuidad o no de la institución monárquica. República o Monarquía, éstas serán las dos ideas que polarizarán y configurarán desde el primer momento a las fuerzas políticas sevillanas" 30 .

Queda así muy clara la situación española en esta etapa, en la que las diferentes fuerzas tomaron posiciones y se operó la bipolaridad política e ideológica en grado radical. Remitiéndome de nuevo al caso sevillano, por su significación y posible representatividad, la evolución de dichas fuerzas ayuda a comprender la actitud de la prensa en relación con los acontecimientos políticos y la "opinión" vertida sobre los mismos.

El estudio de las fuerzas políticas sevillanas en los momentos finales de la monarquía alfonsina ha sido realizado en profundidad por diferentes autores $^{31}$. Mi único propósito aquí es el de realizar una breve visión de los mismos. Por un lado, sobresale el Bloque de Izquierdas, al que también se podría denominar 'antimonárquico'. Formado por republicanos, socialistas y algunos liberales, había difundido un Manifiesto cuyos puntos iban dirigidos a la consecución de Cortes Constituyentes, soberanía nacional y liquidación por vía jurídica de la Dictadura. En su seno había decidido mantener la independencia de cada partido. De éstos, el más fuerte era el Partido Republicano Radical, agente tiempo atrás de un importante proceso reorganizativo bajo la dirección en la capital hispalense de Diego Martínez Barrio. Junto a él, los socialistas que, al contrario que en el resto del país, gozaban sólo de discreta implantación. Por su parte, los liberales terminaron abandonando el Bloque por la presencia de los socialistas, culminando de este modo el proceso de disgregación comenzado años atrás. La postura ante los comicios municipales de estas fuerzas fue. más allá de lo puramente local y, así, para los socialistas "el único dilema clave en el momento que vivían era optar por la Monarquía o la República, y todo lo que fuera distraer la atención del elector de esta opción era 'una desviación del camino revolucionario que sigue el proletariado español" 32 . Todavía más a la izquierda de éstos, se encontraban los anarquistas, quienes carecían de una actitud política claramente definida conrelación a las elecciones; y los comunistas, los cuales se presentaron en solitario pues buscaban realizar unas elecciones revolucionarias en contra de una República burguesa como la pretendida por los socialistas.

En el otro lado del escenario político, figuraban las derechas o fuerzas 'monárquicas'. Formadas por numerosos grupúsculos provinientes

(30) ALVAREZ REY, Leandro, Sevilla durante la Dictadura de Primo..., op. cit. pág. 255

(31) Entre ellos destacan; ALVAREZ REY, L. op. cit. MACARRO, J.M.; La Utopía Rewolucionaria. Sevilla en la Segunda a Repüblica. Edita , Monte de Piedad y Caja de Ahorros de Sevilla, Sevilla 1985. Y TUSELL, J.; La Crisis del Caciquismo Andaluz. (1923-1931).
CUPSA, Madrid 1985.

(32) MACARROJ.M.:La Utopía Revolucionaria...op. cit.,pág. 103. 
bien de las fuerzas existentes en la Restauración, bien de las que habían colaborado con la Dictadura primorriverista. En Sevilla, al igual que en el resto de España, se hallaban muy divididas, y en estos momentos se agruparon y reagruparon formando diferentes coaliciones. Finalmente se presentaron a las elecciones municipales de abril de 1931 en dos listas: la Concentración Monárquica que compusieron los conservadores de antaño y la Unión Monárquica Nacional, (prolongación de la Unión Patriótica primorriverista); y la Coalición Liberal Monárquica, formada por los romanonistas, albistas y reformistas. La postura que tomaron ambos sectores monárquicos es confusa. Calificada de 'plural' por Tusell y de 'reduccionista' por Macarro, se ciñó a una defensa de los principios tradicionales. De cualquier modo, este no saber permanecer unidos frente a un enemigo cada vez más fuerte y la carencia de una propaganda inteligente encauzada a divulgar la importancia del momento histórico son algunas de las causas que, para Tusell, ayudan a comprender la victoria electoral de los republicano-socialistas del 12 de Abril de 1931.

Hasta aquí la somera descripción del marco político sevillano en el momento inmediatamente anterior a la proclamación de la República. Pero. ¿cómo se mostraron estos a contecimientos en la prensa hispalense?

Comenzando por el decano de los periódicos sevillanos del momento encontramos en esta ocasión los mensajes de El Noticiero Sevillano. Este, (que no se vio con anterioridad por problemas ya citados), era un "diario independiente de noticias, avisos y anuncios" fundado en 1893. Perteneciente a la Editorial Andaluza, le respaldaban hombres de conocida ideología liberal. Así, diario moderado, se inclinó antes de las elecciones por la Concentración Monárquica tras manifestar su desagrado por la forma en que se ha planteado la contienda en referencia con el régimen a seguir en España en vez de hacerlo en torno a los problemas municipales: "lo primero que debieran decirnos los disconformes, los que quieren la revolución, es qué es lo que van a resolver en el Municipio, cómo lo van a resolver y para qué"33.

Tras recomendar el mismo día de las elecciones, en un "Himno Electoral" de "Don Cecilio de Triana", que se votase de forma honrada y que no se vendiesen los votos, el diario hubo de reconocer suequivocación al conocerse los resultados electorales. Lo hizo en un artículo publicado el día 14. En él, después de autoculparse al haber creído que apoyando a la candidatura monárquica interpretaba el sentir general del país, al igual que otros muchos, se felicitó por la magnífica lección dada por el pueblo al "darse la forma de Gobierno que en uso de

(33) El Noticiero Sevillano, 11-IV-1931. 
sus derechos de soberanía crea más conveniente sin salirse para ello de las normas pacíficas". Así, finalmente, tras criticar el "lamentabilísimo espectáculo que han ofrecido los monárquicos con sus minúsculas rencillas", terminó tomando la siguiente postura: "En los actuales momentos, de una gravedad extraordinaria, es lo más patriótico inclinarse ante la soberanía nacional, fuente legítima del Poder.(...)A nosotros, si éste es fiel expresión de los deseos del país, nos parecerá bien"34. Por tanto, pasados los primeros instantes de la proclamación de la República, el periódico optó por buscar la unidad de las diferentes facciones para el mejor desenvolvimiento del nuevo sistema ante la aparición de nuevos partidos. Su fórmula consistió en otra poesía de "Don Cecilio de Triana" titulada "Todos a Una!", la cual terminaba con la afirmación: "iQue divisiones/ no haya ninguna!/ iNi derechas ni izquierdas!/ ¡Todos a una!" ${ }^{35}$.

En consecuencia, en los artículos publicados en este periódico en tales momentos no aparece aludido el tema del caciquismo. Sólo en uno de ellos se puso en aviso a los electores contra la compra de votos; algo normal en las elecciones del pasado. De cualquier modo, excepto esa mención a la práctica oligárquica, el tema del caciquismo no aparece en la opinión vertida en El Noticiero Sevillano bajo ninguno de sus aspectos.

En su ángulo, otra fue la conducta de El Correo de Andalucía. En el tiempo que había durado la Dictadura este no había sufrido variación alguna, por lo que seguía siendo el portavoz de la derecha católica sevillana, derecha que si bien había trabajado con el régimen primorriverista en un principio, se distanció del mismo tras el enfrentamiento con Cruz Conde en 1927, por lo que, al finalizar el periodo aparecía como enconada enemiga del primorriverismo en Sevilla.

En los editoriales y artículos publicados durante la campaña electoral, el periódico se centró en el ataque a la Coalición republicanosocialista. Censuró los manifiestos publicados por ésta, sus propagandas etc, aduciendo su falsedad y la hecatombe de la nación en caso de sutriunfo. Por su lado, pidió que se votase a la Concentración Monárquica por ser en su criterio, la opción positiva de aquella maniquea división, pero sin aportar un programa concreto, a pesar de reconocer la importancia del momento histórico. Para ello, el día de las elecciones recomendó encarecidamente el voto a los monárquicos sevillanos y rogó, incluso, a la mujer sevillana que participase en "la batalla de hoy se libra", como madre esposa y hermana. Sus términos son incontroversibles: "Para impedir suplantaciones, los elementos monárquicos deben acudir a votar en

(34) Ibidem, 14-IV-1931. El artículo está titulado; "Unas elecciones históricas. La Trascendencia del momento que vive España."

(35) Ibidem, 19-IV-1931 
las primeras horas de la mañana. Si encontrasen para ejercer su derecho alguna dificultad, requieran el auxilio de los interventores monárquicos. La fuerza pública que vigila los colegios electorales, impedirá cualquier abuso o coacción que pudiera intentarse"36.

Tras las elecciones y el triunfo republicano la actitud del diario no cambió demasiado. Después de mostrar su malestar por los resultados y argumentar que "existe manifiesta desproporción entre los hechos consumados y los que se teme o susurra como consecuencia de los mismos", recomendó serenidad y calma a los monárquicos pues "la Religión, la Patria y la Monarquía requieren en estos instantes el entusiasta esfuerzo de todos. (...) Rehechos y decididos, volvamos otra vez a nuestros puestos. La victoria enemiga es más aparatosa que real, y hasta puede que sea ella misma nuestros mejor aliado en las próximas contiendas" ${ }^{\prime \prime}$. A pesar de ello, no dudó después en ofrecer su ayuda a aquellos que representaban "los principios de orden y autoridad". No dudó en artículos posteriores en criticar duramente a los que no coincidían con su ideología, sobre todo en referencia con la religión, y terminó criticando la validez del advenimiento de la República: "¿Cómo explicar que el resultado de unas simples elecciones municipales que no han señalado mayoría republicana sino en las principales capitales haya decidido a algunos por una de las dos soluciones?"

En relación al tema del caciquismo, El Correo no lo anotó de forma nominal. Sólo se vislumbra indirectamente en la propaganda publicada el día 12 cuando, en primer lugar, pidió se votara temprano para evitar posibles fraudes, y en segundo, cuando en un artículo firmado por "Cándido" se criticó el que personas "obligadamente conservadoras" trabajasen "solapadamente determinados nombres republicanos" advirtiendo que "los familiares protegidos ventilan sólo en la elección de hoy la comandita financiera que les permitió escalar a pesar de su insignificancia, lacandidatura republicana" ${ }^{39}$. Escasas referencias que solo aparecen el mismo día de las elecciones producidas quizá por el recuerdo de lo ocurrido en las últimas celebradas ocho años atrás, y al posible camaleonismo político de algunos conservadores, pero que no afectaron a la propaganda vertida, ni antes ni después de las mismas.

En su andadura clásica, El Liberal, continuó sin cambios mencionables, permaneciendo a su frente José Laguillo. Eso sí, este diario se mostró favorable a la República durante la campaña electoral

(36) El Correo de Andalucia, 12-IV-1931.

(37) Ibidem, 14-IV-1931.

(38) Ibidem, 22-IV-1931.

(39) Ibidem, 14-IV-1931. 
como puede observarse en un artículo de Pedro Fernández Cuesta del mismo día 12 que aseveró: "Indiscutiblemente existe en España una reacción tan favorable a la república, que para los más constituye un postulado y la negación de esta verdad sería la negación de la realidad"40. En dicho artículo se abogaba por la posibilidad de la convivencia entre República y la Tradición, la Religión y la Caridad, aunque sin el fanatismo religioso. Cabe también destacar la petición de la amnistía firmada por "Futurus" en la misma edición. Tras proclamarse la República, como era lógico esperar, la actitud del periódico fue de franca y grande alegría, como lo muestran todos los artículos aparecidos en los dias sucesivos. En ellos, la continúa felicitación por el logro conseguido sea por voz de personajes importantes en la vida política española que usan el diario como catalizador de "opinión" -como fueron Gregorio Marañón, Ortega y Gasset, Alcalá Zamora, etc-, sea por los editoriales. En todos estos, además de acatarse la proclamación de la República como algo inevitable por ser designio de la ciudadanía, -término ya repetidamente usado en los artículos de Laguillo con motivo de la proclamación de la Dictadura-, se hace por ser, además de algo positivo para todas las capas sociales, la única esperanza para el futuro de España. Sirva de ejemplo este párrafo de un artículo firmado por Luis Pidal Rodrigálvarez: "iEspañoles! Roncos de gritar vivas que hasta hace horas fueron sediciones, lleno el corazón de esperanza y de amores, unidos todos, clamemos por un porvenir próximo y glorioso, por una definitiva conquista que ya nadie podrá arrebatarnos, porque la llevamos muy dentro de nuestras almas./ ¡Viva España!/ ¡Viva la República!”‘1.

Si la República aparece como la redentora de todos los males de la patria para El Liberal, es fácil imaginar que lo será en oposición al nefasto sistema anterior. Llegan a pedir responsabilidades ensu combate contra el caciquismo: "Ayer ha terminado en España el caciquismo; ha terminado la influencia política del mal sacerdote que pone á servicio de un interés su sugestión sobre las conciencias; ha terminado el mito de la perspicacia de la vieja política, que jamás contó con el pueblo; ha terminado el tiempo en que se compraban los votos por el dinero ó por la violencia; ha terminado, en fin,la leyenda de la España sin pulso" " Como puede verse en él, el caciquismo aparece como uno de los males del pasado que ha concluido con el cambio de régimen, lo mismo que la oligarquía. De hecho, es en este artículo en el único que aparece nominalmente el caciquismo, sin embargo las referencias a las prácticas oligárquicas, di-

(40) El Liberal, 12-IV-1931.

(41) Ibidem, 16-IV-1931

(42) Ibidem, 14-IV-1931. Procedente de una entrevista con el doctor don Gregorio Marañón. 
recta o indirectamente, aparecerán en algunos otros. En todos se hacen como una evocación del pasado, a excepción del editorial del día 14 en el cual se comenta la venta de algunos centeranes de votos en las elecciones del día 12.

En otra parcela, es interesante la actitud de La Unión. Este diario, órgano de la Unión Comercial, había sufrido paralelamente los cambios de la misma. Así, convertida la Unión Comercial en sostén de la Dictadura en Sevilla en la última fase de la misma, el periódico se convirtió en su defensor. Por ello, en este momento de transición fue el diario que más férreamente defendió los intereses monárquicos. Su gesto en la campaña electoral en este sentido es patente, inclinándose por la lealtad absoluta al Trono. Por un lado recomendó votar a la candidatura de Coalición Monárquica, aduciendo los valores tradicionales: "el amor a la Patria no se concibe sin la solidaridad efectiva con su pasado.(...) Patria, Religión, Familia; estos y otros principios, que son la base de toda sociedad civilizada, se mantienen y defienden al defender la Monarquía, frente a la Revolución, que amenaza destruirlo todo. La Revolución es un postulado negativo..." ${ }^{43}$. Frente a tales tópicos monárquicos, incluyó, asimismo, las críticas a los mítines y a la propaganda de la oposición republicanosocialista, aunque también criticó la conducta de los propios monárquicos "faltos de espíritu ciudadano" y de los ciudadanos en general, quienes prestaban más atención a un partido de futbol que a la política. Este diario exhortó a los electores para que fuesen a votar a primeras horas de la mañana a fin de impedir votos falsos.

Cuando son conocidos los resultados de las elecciones, el mismo día 13, publicó un artículo titulado, 'Monárquicos ayer; Monárquicos boy más que ayer' de su director domingo Tejera, en el que, defendiendo más fuertemente que nunca dicho ideal, se achacó a la negligenciade los políticos de esa ideología la pérdida de las elecciones confiando en la continuidad del régimen. Esto explica que, cuando conoció al día siguiente la proclamación de la República, el diario no cambiase ni un ápice sus palabras y continuara proclamando las mismas ideas, a la par que reprochara a $E l$ Liberal como recibimiento positivo que hiciese en su día de la Dictadura. Mostró, pues, su talante monárquico con orgullo. Como hemos podido comprobar, en este último diario no apareció ninguna noticia sobre el caciquismo o la oligarquía, a excepción del consejo de votar temprano para evitar posibles suplantaciones.

Para finalizar encontramos un periódico aparecido en este paréntesis temporal. Se trata de $A B C$ cuyo primer número sevillano data del 12

(43) La Unión, 10-IV-1931

- 
de octubre de 1929 -la edición madrileña nació en 1905-, y a cuyo frente se colocó un miembro de la familia Luca de Tena, Juan Carretero y Luca de Tena, ex-director de El Noticiero Sevillano. Diario de orientación monárquica, mantuvo una clara postura durante todo el periodo electoral en defensa de esta. Así, en los artículos aparecidos en el periodo anterior al 14 de abril, se encuentran afirmaciones rotundas de los valores monárquicos frente a los que llamaban repetidamente "revolucionarios". Como ejemplo de su postura ante las elecciones sirva este párrafo: "Hay una coalición revolucionaria que admite y busca el concurso de todos los elementos negativos, destructores y disolventes del régimen histórico y social de España. Su fórmula es la República, que sólo interesa al grupo más débil y exiguo de los coaligados, (...). A los demás elementos revolucionarios no es lo que más les interesa, ni sólo por ella empeñarían la batalla. El socialismo, que aspira a la revolución social en dosis evolutivas, por método cauteloso, para apoderarse del Estado sin resistencias; el comunismo, que aspira a la aplicación íntegra, inmediata y violenta del mismo ideal por la dictadura del proletariado; el separatismo, que aspira a deshacer la Patria española secular, a romper la unidad de la nación en cantones cabileños, coadyuvan a una revolución que les abre el camino y que al suprimir la Monarquía destroce el baluarte en que se sostiene la Patria unida, la tradición, el régimen social y civil, el orden, la propiedad, la familia y la Religión"44. De este modo, ellos como defensores del orden monárquico pasaron a autodenominarse "antirrevolucionarios": "Patriotas, madrileños, católicos, liberales, propietarios, capitalistas, productores, trabajadores, rentistas, empleados. Todos debéis votar la candidatura antirrevolucionaria" 4 . Junto a esas llamadas de atención ante el "peligro revolucionario", $A B C$ propone "La obligación de votar" invocando a la ciudadaníaespañola para que demuestre sus dotes democráticas atacadas por las izquierdas.

Después de conocerse los resultados electorales con el triunfo republicano, el diario se felicita por la reacción del pueblo, alabando la "legalidad irreprochable" de las elecciones. Sin embargo, a pesar de sorprenderse del triunfo de las izquierdas, $A B C$ reafirma sus ideales monárquicos el dia 14 de abril: "Seguimos y permaneceremos donde estábamos: con la Monarquía constitucional y parlamentaria; con la libertad, con el orden, con el derecho, y nunca fuera de la ley; sometidos a la voluntad nacional, pero sin sacrificarle nuestras convicciones. La Monarquía es el signo de todo lo que defendemos; es la historia de España. Los hombres y los azares pueden interrumpir, pero no borrar, la tradición y la

(44) $A B C, 17$ y 19-IV-1931 respectivamente.

(45) Ibidem, 5-IV-1931. 
historia, ni cambiar el destino de un pueblo" ${ }^{\prime \prime 6}$. Con posterioridad a la proclamación de la República el periódico se mostró bastante moderado acatando en todo momento la voluntad nacional: "Los adversarios con que se inaugura la República lo son también, y en primer término para España. No nos complaceremos en ellas ni en explotarlas para quebranto del Gobierno, ni en contribuir a ningún fracaso suyo cuando con él fracase un interés de la nación." "No alentaremos, pues, las rebeldías militares, y si algún puñado de oficiales impetuosos del Ejército se sublevara algún día, aunque fuese por nuestros ideales, no seríamos nosotros quienes acusáramos de asesinos a los hombres del Gobierno, que, en cumplimiento de un derecho o de un deber, hicieran caer sobre ellos el peso de la ley ${ }^{47}$. No estuvo muy profético el diario en este último párrafo.

Como se ha podido observar, no aparece en $A B C$ ninguna referencia al caciquismo, ni siquiera la indirecta a la posible compra de votos el dia de las elecciones que si aparece en los otros periódicos de orientación monárquica como eran El Noticiero Sevillano, La Unión y El Correo de Andalucia, (en este último aparecía, además, la crítica a determinados antiguos conservadores que habían pasado al bando republicano para defender los intereses económicos de los suyos). Esa repetición del aviso sobre la posible compra de votos puede ser entendida como el resultado, o bien del temor a que en las primeras elecciones habidas en ocho años volvieran a usarse los sistemas del pasado, o bien a que realmente los usos corruptos estuviesen siendo usados. En este sentido, hoy se sabe que los monárquicos intentaron llevar a cabo dicho procedimiento auque sin el éxito de otros tiempos. Como he indicado pues, el caciquismo sólo aparece directamente en el diario El Liberal y lo hace tras las elecciones al referir los males del sistema anterior que cree desaparecidos con él.

Observadas las referencias al tema, he de volver a la pregunta inicial de la Comunicación: ¿había sido superado el problema del caciquismo como asunto de debate público en 1931? Sí tenemos en cuenta el que en 1923 era cuestión obligada y su enorme influencia en la "opinión pública", he de decir que creo que sí. El caciquismo, junto con los usos oligárquicos, fue el asunto más repetido y recalcado en aquel momento, llegando a emplearse como disculpa por quienes, en contra de sus convicciones políticas, aceptaron el advenimiento de la Dictadura militar. Podemos decir, por tanto, que el caciquismo y la oligarquía aparecen en 1923 como las

(46) Ibidem, 14-IV-1931.

(47) Ibidem, 17-IV-1931. 
mayores preocupaciones de la prensa sevillana, convirtiéndose en punto obligado de debate político en el momento del cambio del régimen.

Frente a ello en 1931, tan espinoso concepto aparece nominalmente en sólo una ocasión en El Liberal y en palabras de Marañón al hacer referencia de los malos usos del pasado desaparecidos con el nuevo régimen, -siguiendo así un topismo paralelo al usado en 1923-. Sin embargo, en esta oportunidad, en ningún momento se le trató como un peligro real y cotidiano, a excepción del temor a la compra de votos que, esta vez sí, se incluyó en todos los diarios. Por contra, el testimonio de la Prensa nos dice que el centro del debate político estuvo en 1931 en la dualidad entre Monarquía y República, entre el anquilosamiento y la innovación. Los defensores de la continuidad -El Correo y La Unión en especial-, lo hacen en aras del mantenimiento de los valores tradicionales, y no de los usos. En el lado opuesto, quien vio bien un cambio radical del sistema ante la incapacidad del mismo para regenerarse y solucionar los problemas nacionales: El Liberal.

La pregunta final sería la siguiente: isignifica todo esto que el caciquismo había desaparecido en 1931?. Siguiendo las afirmaciones de Tusell para después de proclamada la República "desaparece, porque los fundamentos mismos de la vida política sufren una transformación total...", debida a la participación de las masas en la vida política. Gracias a éstas, pudieron funcionar los partidos políticos normalmente y no por medio del clientelismo político, y, gracias a esa participación, se llevaron a cabo unas elecciones democráticas con el triunfo de la candidatura republicano-socialista. "Hay, por lo tanto, una diferencia fundamental en el comportamiento político en la Monarquía de Alfonso XIII y en la Segunda República -dice Tusell-. Sin embargo, el hecho de que exista esta diferencia no quiere decir, por supuesto, quedesaparezcan radicalmente aquellos elementos de política personalista y caciquil" ${ }^{18}$. A mi juicio, esos modos de comportamiento político tendrían una transformación muy lenta siguiendo las pautas de la "larga duración". Es por ello que Tusell acepta la continuidad de prácticas caciquiles pero en un grado mínimo, y, nunca, con la fuerza anterior. En conclusión, que para 1931 una cosa fueron los procedimientos políticos y otra los puntos de reflexión que abordó la prensa. al menos en Sevilla.

Aceptando estas afirmaciones y, al hilo de las opiniones aparecidas en la prensa sevillana, opto por creer que el problema del. caciquismo había pasado a un plano muy inferior dentro de las preocupaciones políticas hispalenses. Y esto debido a que, fruto quizás de ese mismo

(48) TUSELL: La Crisis del caciquismo andaluz... op. cit., pág. 459. 
anquilosamiento y falto de respuesta, el sistema oligárquico permaneció inmóvil en Sevilla ante los cambios producidos. El sistema de la Restauración se hallaba al parecer agonizante, y al ser así, nadie, ni unos para defenderlo ni otros para atacarlo, gastó un mínimo esfuerzo en contra de un moribundo extenuado. Por ello, el tema a debate se trasladó hacia el único signo vivo del pasado: la Monarquía, el caciquismo estaba prácticamente muerto $o$, dicho de otro modo, la innovación republicana se entendió como su sepulturera. 